\title{
Writing Beyond the Letter
}

\author{
Marc Wilhelm Küster
}

\section{ABSTRACT}

The ability to write, hence to preserve and share arbitrary words and thoughts, was one of the most important breakthroughs in the history of mankind. It laid the technological basis for what we perceive today as culture, science and, in good part, economy. Nonetheless, writing can encompass much more than just words, and this is an integral, but often overlooked part of it. Until very recently, writing was necessarily bound to the physical medium on which it was written or into which it was inscribed. The physicality of the medium interacted with and often enhanced the purely textual message. These features, which go beyond the encoding of words, are the secondary characteristics of writing systems. They include, but are not limited to typography, and often serve, consciously or not, the transmission of additional messages beyond the purely textual content.

If the study of writing itself is still largely in its infancy, this is even more true for the study of secondary characteristics, which is an integral part of grammatology. Beginning with a taxonomy of these secondary characteristics, this article looks in more detail at two non-typographical characteristics, namely ordering and punctuation. This short sketch of a cultural history of ordering and punctuation begins with the role of ordering in the initial invention of writing over its use across the millennia. It ends with the contemporary use of special punctuation marks to encode emotions.

\section{WHAT IS WRITING?}

Writing is a durable medium, involving sounds that represent words and sentences, and entities that ultimately represent meaning. This invention may well count amongst the greatest achievements of mankind, laying, as it did, the technological basis for what we perceive of today as culture - or, as P. Daniels put it beautifully and succinctly, 'Humankind is defined by language; but civilisation is defined by writing.' ${ }^{1}$ As far as we know, writing was invented a number of times independently in human history, notably in Mesopotamia, in China and in Mesoamerica. ${ }^{2}$ Its development followed the same macro-pattern each time.

To concentrate on the earliest of script inventions in Mesopotamia, the earliest forms of what would become cuneiform writing were largely restricted to depicting concrete concepts (pictographic characters) such as head, man or grain. These shapes were initially clearly recognisable as depictions, for example grain:

The limitations of such a proto-writing system are flagrant: beyond the biggest conceptual restriction of not being able to represent abstract concepts, verbs or adjectives, it needs a potentially unlimited number of pictograms, is cumbersome to write and impossible to remember. To alleviate the problem of representation from the earliest days of pictograms - indices in the terminology of Charles Sanders Peirce ${ }^{3}$ - were complemented by purely conventional symbols, such as the cross that stands for sheep: ${ }^{4} \mathrm{H}$ Such symbols extended the expressivity less easily represented objects to some degree.

However, this does not solve the fundamental problem. All three independent inventions of writing then stumbled upon the same path to full writing: Only by moving from the concept of a pictogram to its sound value and by using this sound value completely independently from its original meaning did it became possible to write arbitrary words (rebus principle), and the ability to write any word is what defines a complete writing system. The resulting system was standardised over the centuries, but it remained highly ambiguous because most sound values could be represented by multiple cuneiform characters and, in turn, most cuneiform characters could represent multiple sound values. ${ }^{5}$

We will see many of the same mechanisms in action in the current usage of emoticons and punctuation.

\section{BEYOND LETTERS: SECONDARY CHARACTERISTICS}

The ability to write, hence to preserve and share arbitrary words and therefore thoughts, was a major breakthrough in the history of mankind. However, writing can pen much more than just words and sentences, ${ }^{6}$ and this is an integral, but often overlooked aspect. Writing was until very recently necessarily bound to the physical medium on which it was written. 
The physicality of the medium interacted with and often enhanced the purely textual message Dating from Sumerian times, particularly important texts such as legislations were frequently inscribed in stone for better durability and visibility. Scribes used a particular script variant for this purpose. They might also combine the text, as in the Akkadian Codex Hammurabi, with artwork to highlight the particular importance of the inscription. The Egyptian culture pushed this much further with a strong iconography of writing in hieroglyphic texts. Holy texts have been and are frequently written on particularly valuable media. Love letters, even in today's electronic age, are often hand-written on special paper. Writing can thus capture emotions and subtexts that are not present in any of the graphemes, but instead are derived from their interaction with their basic medium to encode additional ideas, just as the intonation of the human voice can transmit messages beyond the sequence of phonemes that make up spoken language. These ideas may even contradict their explicit message:

\begin{tabular}{|c|c|c|c|c|}
\hline $\begin{array}{l}\text { LEFT } \\
\text { right }\end{array}$ & $\begin{array}{l}\text { left } \\
\text { RIGHT } \\
\text { left }\end{array}$ & & $\begin{array}{l}\text { upper } \\
\text { LOWER }\end{array}$ & $\begin{array}{l}\text { UPPER } \\
\text { LOWER } \\
\text { upper }\end{array}$ \\
\hline LEFT & $\begin{array}{l}\text { right } \\
\text { left }\end{array}$ & $\begin{array}{l}\text { upper } \\
\text { lower }\end{array}$ & LOWER & \\
\hline
\end{tabular}

Figure 1. Interference of primary and secondary characteristics in a writing system. Figure inspired by Daniel Kahneman, Thinking, Fast and Slow (New York: Farrar, Straus/Giroux, 2011), Chapter 1,

We intuitively expect the position on the page and the capitalisation to align with the explicitly written message. Forcing a reader to call out if a word is written in lower or upper case is easy for the left column - no conflict between text and capitalisation - but is much more difficult for the right column, where both clash. Similarly, calling out the position (left or right) is much easier for the right column than it is for the left, where again the written text and the observed position are contradictory. For the same reason, it is confusing to identify colours when the colour used to print the name of the colour and the given colour are not the same; for example, blue or orange. ${ }^{7}$ We have similar problems with processing information whenever the textual message and its representation clash, and can interpret it much more easily when they reinforce each other. To capture the distinction between the primary and secondary messages, I have introduced the concept of secondary characteristics of writing systems. Typography, the main topic of this special issue, exploits these secondary characteristics to underline and sometimes to nuance the text's main message. So does punctuation, of which smileys can be said to be a contemporary extension, and so does a seemingly completely different phenomenon, the internal order of characters within a writing system.

In my study Geordnetes Weltbild: An Ordered View of the World, I have tried to give a taxonomy of secondary characteristics, slightly extended here: ${ }^{8}$

- Relative order of characters in a writing system

- Use of glyph variants, for example:

- Font variants, such as different fonts or the different shapes of Chinese characters in China, Japan and Korea, including the use of historical number signs such as the use of Arabic or Roman numerals

- Font styles such as bold face or Italics

- Font sizes

- Usage or non-use of certain ligatures or ligature groups

- Horizontal or vertical arrangement of words and lines (including writing Direction)

- Colours

- General aspects of page layout

- Punctuation

Comics illustrate many secondary characteris tics better than words can: ${ }^{9}$

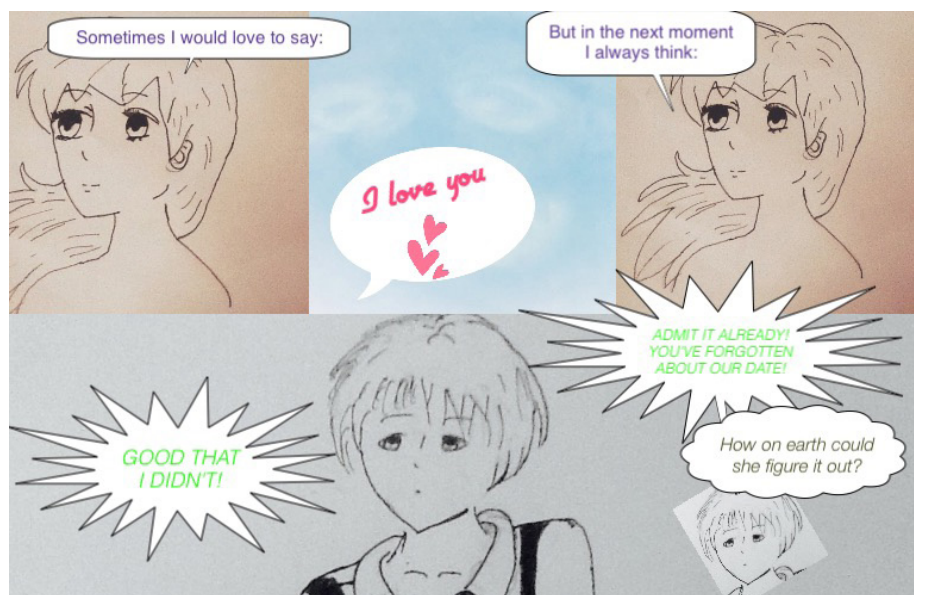

Figure 2. Use of fonts, font sizes, font styles, pictograms and punctuation to encode emotions, language and differences. Created by Nicki Wächter for this article, published with permission.

This article will not examine glyph variants and page layout, which are more the purview of typography stricto sensu, but will investigate two of the remaining characteristics, ordering and punctuation in more detail. 
In a clan or village culture, product quantities are typically small and transactions simple. The limited stock is easy to find in whatever barns there might be, and arrangements are easy to remember.

Sorting - the arrangement of objects or information according to predefined schema with the goal of finding them again - becomes a necessity only when quantities are no longer manageable by memory alone. Sorting is not necessarily linked to writing; in fact, it normally is not. It also does not have to be linear. Any agreed scheme to put some types of tools or goods always in one place and others in another is sorting. Ordering in the sense in which I use the term is the sorting of words or phrases into a linear sequence, or to provide the formal definition: 'a process by which two strings are determined to be in exactly one of the relationships of less than, greater than or equal to another.' ${ }^{10}$ In other words, ordering is any process whereby a series of written words or phrases is placed in a predefined sequence to find them more easily.

Ordering is in the West inextricably linked to the alphabet, but this has not always been so. As with any human technology - for writing and ordering are technologies - ordering has a history. Küster's Geordnetes Weltbild was the first overview of the cultural history of ordering from its earliest beginnings up to the present. With the exception of the subsection on the heavenly order, this article is based on that work.

\section{The origins of ordering}

When writing was invented in Sumer, it was initially used above all to improve accounting. The complexity of the city states' economy had reached a degree that meant it was no longer feasible to manage stocks, taxes and payments by relying on memory alone. Unfortunately, mastering the long lists of graphemes for stocktaking was difficult in itself. In order to facilitate learning them by heart, they were from presented in so-called lexical lists that presented the symbols in semantic units the earliest known phases of writing onwards.

The list of which we have the oldest specimen is LÚ A, a list of professions containing 140 entries, with the earliest copies coinciding with the emergence of proto-writing in the Uruk IV period, from about 3300 to $3100 \mathrm{BC}$. This list was transmitted essentially unchanged for at least a millennium.

LÚ A provided a one-dimensional picture of Sumerian society from the ruler (namsita) downwards, including a temple functionary (luhšsa) and a potter $\left(\right.$ bahar $\left._{2}\right) \cdot{ }^{11}$ Everybody could find his place on this list. However, LÚ A was by no means the only list that defined hierarchies in a given domain. Even in the archaic period Oracc, the 'Digital Corpus of Cuneiform Lexical Texts' (DCCLT) presents, in addition to the list of professions in LU A, lexical lists of animals, birds, cities, fish, food, metals, officials, plants, vessels and garments, wood, and generic word lists, typically having between 50 and 150 entries each in their surviving forms. Writing itself gained in status through this - the early dynastic profession list ED Lu B puts the scribe (umbisay) at the top of the list, as writing created 'new institutions for information storage and accountability, forming something that probably had prestige and symbolism through its mere existence. ${ }^{12}$

Over time, the number of lists multiplied, although many of the archaic lists continued to be used essentially unchanged over the centuries, often preserving an increasingly archaic world view across time. Just as the Sumerian script was transferred first to Akkadian, a Semitic language in close contact with Sumerian, and then to other Semitic and Indo-European languages in the Near East, these lists were transferred to the borrowing languages and cultures.

Thinking in linear lists was - or probably became through writing itself - a constitutive feature of Sumerian and later Akkadian and Babylonian culture and science. Von Soden goes so far as to characterise Sumerian science as a science of lists ('Listenwissenschaft') based on classification ('Ordnungswissenschaft'). The list had developed from a primarily mnemonic device to a thinking tool. Its primary means of expression was not the narrative text with an (ideally) logically connected sequence of statements, as characterises Western science and philosophy from Greece onwards, but hierarchy and linear classification. ${ }^{13}$

\section{The first dictionaries: Ebla}

Over the centuries, Sumerian declined increasingly as a spoken language, becoming extinct by around 2000 BC. However, its status was such that it remained in use as a written language of culture and cult for almost two more millennia, not unlike Latin in Europe after the Carolingian renaissance.

From an early period, Sumerian was the object of study for many scribes in the Near East, for whom it was a foreign language, requiring tools for language learning, notably dictionaries. Of particular importance in this regard were the lexical lists and dictionaries that were found in Ebla's ${ }^{14}$ royal library dating from the period between approximately 2500 and 2250 BC, a time at which Sumerian was still a living language. Amongst the many tablets are no less than five 
copies of the LÙ A profession list, ${ }^{15}$ largely used in an educational context. They demonstrate once more the stability of lexical lists almost a millennium after their earliest attested specimen. Obviously, mastering the canonical sequences of the different concepts was considered a key aspect of learning the Sumerian language and culture. In fact, the tablets in the library itself seem to have been classified according to subject matter. ${ }^{16}$

However, "perhaps the most important part of the texts is a collection of thirty-two bilingual dictionaries, most of which seem to be copies of three basic word lists that together comprise about three thousand words of Eblaite. ${ }^{17}$ These dictionaries are important for Assyriologists, as they, together with additional syllabaries, allow us to know how Sumerian was pronounced in a time in which it was still a living language ${ }^{18}$ Furthermore, the library also contained monolingual Eblaite wordlists, which no longer reflected Sumerian semantics for the first time. Instead, these wordlists ${ }^{19}$ were ordered based on cuneiform signs; thus, a language learner could locate an unknown word in the list with ease. The scribes would never have dared to take similar liberties with the established Sumerian word lists, but they obviously felt justified in innovating with regard to their own language. In this way, the Eblaite scribes had created the first known example of a principle that we take for granted: ordering not by semantics, but by the formal components of a writing system. They transferred this invention to syllabaries that combined Sumerian characters with their rough transcription into Eblaite syllables, and true bilingual dictionaries with about 15 oo terms, 'the most ancient dictionaries known.' ${ }^{20}$ The dictionaries were a popular invention that the library stocked in multiple copies.

Semantic ordering necessarily assumes that a concept has a clearly defined place relative to all other concepts, and that this understanding is shared by all users. Unknown concepts do not fit in easily. The Eblaite scribes were probably unaware of it, but they - or perhaps their unknown predecessors, who did not leave any trace behind - had invented a technology that allowed to bring order to arbitrary knowledge. In this way, they had moved from a technology for classifying in a closed world, the static environment of a lexical list, to a technology for dealing with an open world. In so doing, they had imbued the Sumerian writing system with the inherent capability to order and retrieve any type of knowledge.

Under the influence of Sumerian culture, cuneiform script never realised the potential of this invention. Dictionaries continued to exist, particu- larly after Sumerian had ceased to be a spoken language, but the paradigm of semantically lexical lists remained dominant. It would take two more millennia and a new cultural context for the idea behind ordering by character as an integral part of the writing system itself to be fully exploited.

\section{Birth of the alphabet}

The cuneiform script and its Egyptian counterparts remained unchallenged for another thousand years. Egyptian writing had, from its early stages onwards, existed in two forms that we call hieroglyphic and hieratic, 'systematically almost identical and mutually convertible. ${ }^{21}$ Hieratic was the variant most commonly used in everyday writing contexts, being less obviously pictographic than were hieroglyphs and thus faster to write. Since Alan H. Gardiner's 1916 publication, it has generally been accepted that today's alphabets are indirect descendants of hieratic writing. ${ }^{22}$ They are indirect, as Egyptian writing in general shared the same ambiguities as cuneiform. The basis of the (largely) consonant-based Semitic writing system was already present in its Egyptian source, as the 'Egyptian hieroglyphic system eschews vowels, and comprises a full alphabet of consonants besides its biliteral and triliteral signs, ${ }^{23}$ but it took nothing less than a conceptual revolution to extract an alphabet from it.

Egyptian and Semitic populations intermingled on the Sinai Peninsula. In 1905, a series of inscriptions dating from about $1500 \mathrm{BC}$ were discovered in the turquoise mine of Serăbiṭ el-Khàdim, consisting of 'a form of writing almost certainly alphabetic in character and clearly modelled on the Egyptian hieroglyphs' ${ }^{24}$ with a relatively small number of distinct character shapes. It is largely accepted at present that the Semitic letters derive from this early script and are based on the so-called acrophonic principle, whereby each letter depicts an object that starts with the sound that this letter represents:

The supposition is, that 'alf being the Semitic word for ox, an ox's head was depicted to indicate the soft breathing ['] with which this word begins; similarly bet being the word for house, the miniature picture of a house supplied the letter $\mathrm{b}$. The principle underlying this method of creating alphabetic letters is known as the principle of acrophony [...].

At all events any hypothesis that makes of the protoSemitic script a variety of pictographic writing has all the anthropological probability on its side. ${ }^{25}$ 

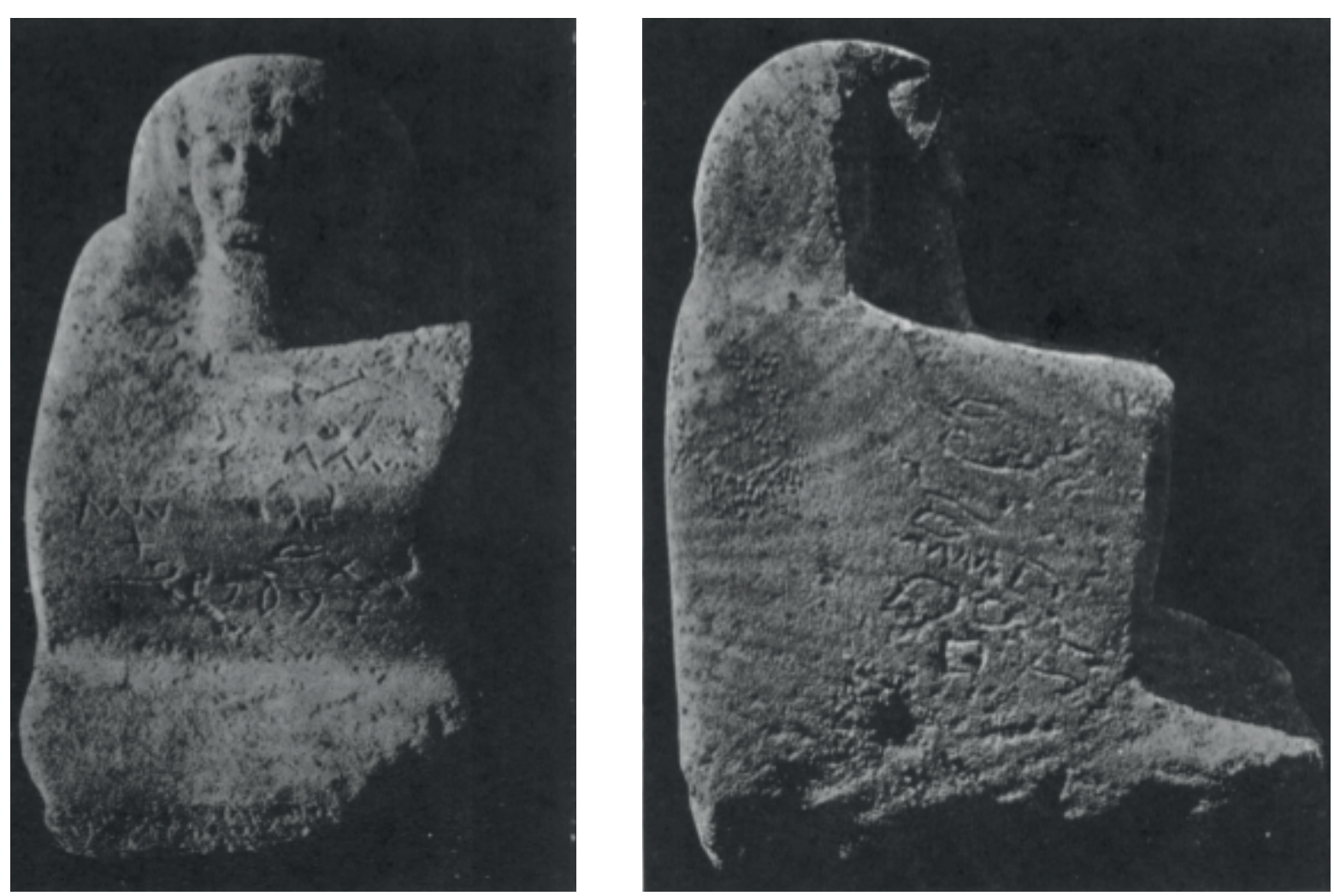

Figure 3. Statue from Serǎbiṭ el-Khàdim with a proto-Semitic inscription, reproduced after Alan H. Gardiner, "The Egyptian Origin of the Semitic Alphabet," The Journal of Egyptian Archaeology 3. no. 1 (1916): 16, plate IV.

The recent discovery of Semitic descriptions in a clearly alphabetic script dating from about 19001800 BC near Thebes in Upper Egypt strengthens this hypothesis. ${ }^{26}$ As was the case for Sumerian culture, Egyptian culture was fundamentally conservative, and the essentials of the Egyptian writing system did not change over the nearly four thousand years of its use. However, scribes clearly felt more at liberty to deviate from tradition in hitherto unexplored areas. The writers of these short inscriptions, be they the Semitic immigrants themselves or their local Egyptian scribes, ${ }^{27}$ were fully aware of hieratic writing, but extracted from it only the minimum number of signs. Following the Egyptian model, they selected signs that depicted objects related to the sound they represented, resulting in a simple and easy writing system that not only the elite scribes, but everybody could master. It was this invention by or for simple immigrants that quite literally democratised writing - one of humanity's most influential inventions.

However, one aspect of the alphabet was most likely still missing - ordering. While the Egyptian and Sumerian writing systems were both a combination of logographic and syllabic writing, Egypt had no list culture comparable to that of Sumer. Those rare lexical lists that have come down to us are much younger - the earliest ones date from the eighteenth or seventeenth century $\mathrm{BC}^{28}$ - and thus postdate the invention of alphabetic writing. Therefore, I assume that the Proto-Sinaitic script was created without an inherent ordering of its characters, and acquired one only after it took root in the Levant, which had been in the cuneiform sphere since at least the time of Ebla.

When we do find the first abecedaria in the thirteenth and twelfth century BC, we observe two conflicting orders, a fact that would be difficult to explain if order had been a feature of the alphabet from the beginning. The North Semitic order is first evident in a twelfth century abecedarium found in 'Izbet Sartah, not too far from present-day Tel Aviv. With one exception, it corresponds to the order that would become canonical in the Phoenician and Hebrew alphabets and which, through the Phoenician alphabet in particular, would influence the order of all Western alphabets.

The South Semitic order survives today in a modified form in the Ethiopic syllabary. The earliest attested example is a thirteenth cuneiform tablet found in Beth Šemeš. Clearly under the influence of the new alphabetic script, scribes invented versions of the South Semitic script using cuneiform characters and imbued it with an order (see Figure 4 ). There are other finds of abecedaria with the South Semitic order; there are examples from Ugarit $^{29}$ and from South Arabia that corroborate these findings.

I am convinced that the Sumerian list culture was deeply uncomfortable with a set of signs, which were also terms via the acrophonic principle, without an inherent order. Following the model of the lexical lists, scribes in the cuneiform tradition tried to 


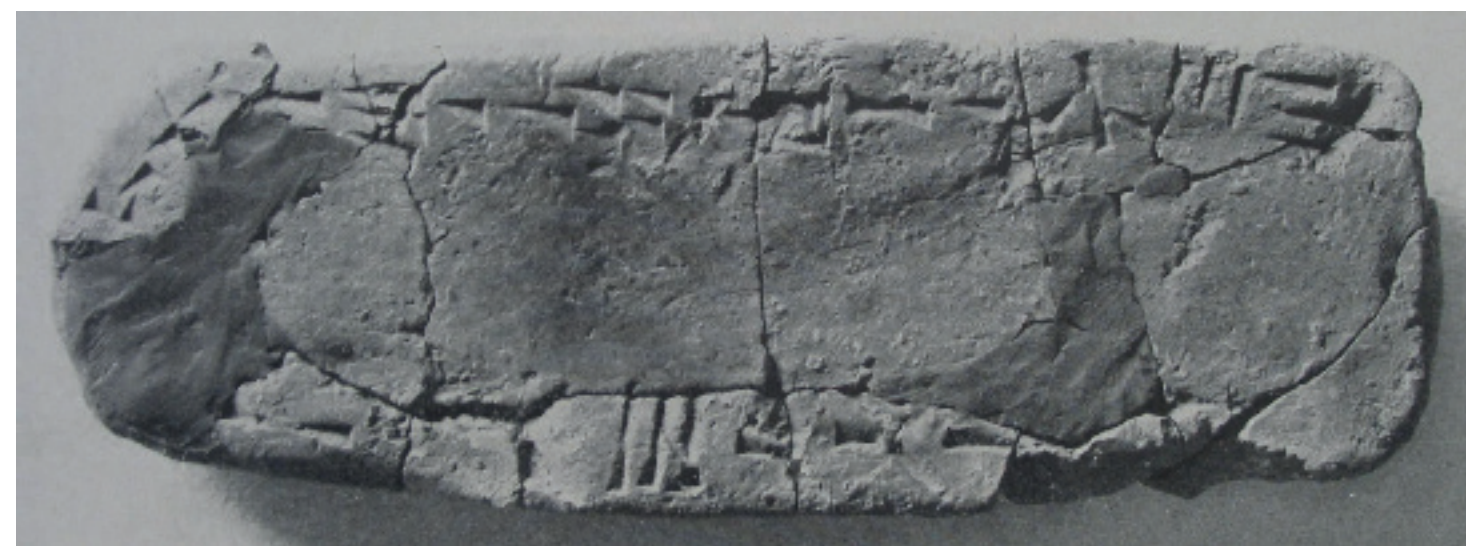

Figure 4. Abecedarium of Beth Šemeš, cf. Elihu Grant, Rumeileh Begin Ain Shems Excavations (Palestine), part III, vol. 5, Biblical and Kindred Studies (Haverford: Haverford College, 1934), Plate XX.

find clusters of related terms, beginning with the ox, a symbol of fertility and strength, as well as being a representation of $\mathrm{Baal} .^{30}$

\section{Greek and the reinvention of dictionaries}

The Greek alphabet was a conscious adaptation of the Phoenician alphabet, and Greeks initially

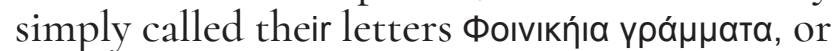
Phoenician letters. Writing took hold quickly in Greece, and writing was ubiquitous amongst Greeks within a few decades. The earliest known Greek inscription, still running right-to-left, dates from about $735 \mathrm{BC}$ and is scratched onto a wine jug found in Athens in the Dipylon cemetery. However, for centuries, no single Greek alphabet existed. Instead, each region initially had its own alphabet variant with quite different usage patterns and specific letters. ${ }^{31}$ However, all variants partook in the Greek script's biggest innovation, the full writing of vowels. In fact, Greek inflections and conjugations depend heavily on vowels, and a script without vowels would have been impractical. The largely phonetic writing lowered the entry barrier still further, making writing an essential tool in Athenian democracy, where votes were often written on pieces of pottery (ostraca).

In addition, all variants of the Greek alphabet shared the same basic order, starting with the order of those characters that the Greek alphabet had adopted directly from its Phoenician predecessor. In addition, the vowels occupied the same positions across the spectrum, including the addition of $Y$ (ypsilon, $u$ ) after tau. Some characters, particularly the digamma $F$, the qoppa $Q / \mathrm{Q}$ and the sampi $\exists$, existed only in some variants. $F$ and $Q$ were placed after $E$ and $\Pi$, respectively, taking the positions of their Phoenician predecessors waw and qoph, while $\rightarrow$ is a more recent letter of unclear provenance and was added after $\Omega$. All three letters dropped out of active use in the fifth century BC at the latest, but in an amazing demonstration of the stability of ordering as a cultural tradition, they survive to this very day as the number characters for 6, 90 and goo, respectively, taking their numeric value from their position in the alphabetic sequence. Not all local variants used the consonant clusters $\varphi, X, \Psi$ that followed in alphabetic sequence ${ }^{22}$ after Y. What we now naturally consider to be the last character, $\Omega$, was a somewhat late Ionian addition that only became standard usage in the fifth century BC. Since the alphabetic order up to $\Psi$ was already canonised at that point, $\Omega$ was not inserted after $O$, from which it is derived, but was added to the end instead.

The Ionian variant of the Greek alphabet, and in particular that of Milet, also became increasingly popular in other Greek regions. In a singularly modern approach, in $403 \mathrm{BC}$, Athens voted to replace the local Attic alphabet with the Ionian one for all official documents and in all elementary education. 33 The architect of this first known example of a script reform by popular acclamation, the Athenian politician, Archinos, had prepared for the vote by compiling a pamphlet giving the reasons for this change. His primary argument was that the Ionian alphabet was quasi-mandated by nature. The double consonants $\varphi, X, \psi$ were said to be necessary additions to align the alphabet with the three dyads of (we can assume) Pythagorean heavenly harmonics. In this way, the alphabet would fully reflect the natural order of things or, as the Pythagoreans claimed, 'that the interval from $\alpha$ to $\omega$ in the alphabet is equal to that from the lowest note of a flute to the highest, whose number is equal to that of the whole system of the universe.' 34

The years around 400 BC were in many ways a turning point in Greek history. During this time, the classical period of the Greek city states was eclipsed, exhausted by decades of infighting, particularly between Athens and Sparta. The death of Socrates in 399 BC marked the beginning of Platonic and Aristotelian philosophy, with 
Macedonian hegemony over Greece and the Hellenistic period clearly on the horizon.

In Hellenic times at least, Archinos' plan to integrate the Ionian alphabet and its order into education was a complete success. Primary education was centred on the alphabet. Surviving school exercises from Hellenistic and Byzantine times show that the pupils had, in levels of increasing difficulty, to learn the alphabet itself first, and then write syllables or even all possible three-letter combinations in alphabetic sequence, followed later by complete words, and finally by sentences ordered alphabetically by the first letter. Writing and ordering were thus inextricably intertwined.

Hellenism saw also the rebirth of alphabetically ordered dictionaries. The first such lists were glosses of Homer, although few details have survived. The 'earliest known specimens of Greek lexicography,'35 papyri from around $250 \mathrm{BC}$, from the early Ptolemaic period, gave alphabetically ordered glosses of unusual words, arranged by the first two letters. This tradition continued uninterrupted into the Byzantine era, leading to massive dictionaries such as the one compiled in the fifth century AD by Hesychios of Alexandria, containing over fifty thousand lemmata in alphabetic order, or specialised works such as Johannes Philoponos' dictionary of Greek homophones of the same period. The latter illustrates the sound changes in Greek during the millennium that separated his time from that of classical Athens. Many words were now homophones, but not homographs, and their distinction in writing had to be learned.

Alphabetically arranged encyclopaedias complemented the dictionaries, culminating in the tenth century Suda that, with its thirty thousand lemmata, was in many ways the summa of classical knowledge. The Suda was ordered alphabetically but, breaking with thepast, it modified the alphabetic order to place letters that sounded identical next to each other, resulting in $\alpha \beta$ Y $\delta$ a $\varepsilon \zeta \varepsilon ı \eta ı$ $\kappa \lambda \mu \vee \xi о \omega \pi \rho \sigma$ т о $\cup \varphi \times \Psi$. Double consonants, which by that time were a purely orthographic convention, were arranged alongside their single counterparts. The Suda - similarly to some of its contemporary Latin dictionaries - did not order its lemmata strictly by grapheme, but rather by phoneme, giving a clear idea of the actual pronunciation of early Medieval Greek and Latin at the same time. ${ }^{36}$ The Suda's approach is actually every bit as sophisticated as the modern phonetic algorithms used for phonetic searches in databases. Thus, this rearrangement consciously broke with strict adherence to tradition in an effort to, in modern terms, improve the user experience.

\section{Heavenly order}

As seen, the order of the Greek alphabet was identified with heavenly harmonics. The Pythagoreans were, however, neither the first nor the last to use the alphabetic order in this way. Anaphora, or the repetition of the same word at the beginning of each line, was also a popular rhetoric device in oral cultures. It was easy to generalise this to quasi-acrostics in which each line started with the same sound or syllable, then to the introduction of full acrostics in writing, where the first characters or syllables form a word or sentence. Examples of such (obviously non-alphabetic) acrostics date from Akkadian ${ }^{37}$ times and were quite popular at the seventh century Babylonian court. ${ }^{38}$ The hidden acrostic messages were often considered to be imbued with a certain magical power. ${ }^{39}$

Hebrew poetry clearly liked acrostics, but went a step further towards alphabetic acrostics in which the first characters of each line followed the alphabetical order. The Old Testament contains about a dozen acrostics, particularly in the Psalter, of which the longest and most famous one is Psalm 119. The alphabet and its order symbolised God's perfection - 'the alphabet is a ready metaphor for totality'. ${ }^{\circ}$ The poets used this implied message skilfully. In Nahum 1, 1-11 the prophet imagines the destruction of Israel's enemy Assyria. The presentation begins with an alphabetical acrostic from aleph to kaph, but is then overtaken by imagery of destruction. With the destruction of the enemy the alphabetical order also breaks down symbolically.

The idea of alphabetical order symbolising perfection has since always been present in both Jewish and in Greek culture. Its ultimate apotheosis is in the Book of Revelation, as 'I am the Alpha and the Omega, the beginning and the end' (twice, Revelation 21:6, and 22:13, referencing Isaiah 44:6), and "I am the Alpha and the Omega," says the Lord God, who is and was and is to come - the Almighty' (Revelation 1:8). This metaphor became very popular at an early stage in Christian iconography, often in combination with the Chi-Rho

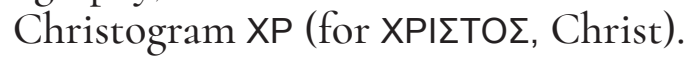

Santa Maria Maggiore, the core of which was completed by 440 following the Council of Ephesus, was placed under the protection of two ChiRho Christograms with alpha and omega. One is part of the church's triumphal arch with its fifth century mosaics directly above the main altar of the basilica, while the other is the centre stone of the apse with its thirteenth century mosaic. In both cases, the symbol is associated with Christ Pantocrator, Christ the ruler of everything. He is described in the Book of Revelation as the judge 
at the end of things, which at the same time is the beginning of the heavenly Jerusalem. In Figure 5, the Christogram is directly associated with Christ's imperial throne, which is also the throne of the pope as bishop of Rome (Pope Sixtus III as 'episcopus plebi Dei', bishop of the people of God), flanked by the apostles Peter and Paul. On the throne we see a crown and a cross and, at its feet, the scroll of the seven seals of the revelation. ${ }^{41}$ Peter (to the left) and Paul in turn also mirror alpha and omega; in other words, the first, Jewish mission (alpha) and its extension of the covenant to the gentiles through Paul's missionary work (omega).

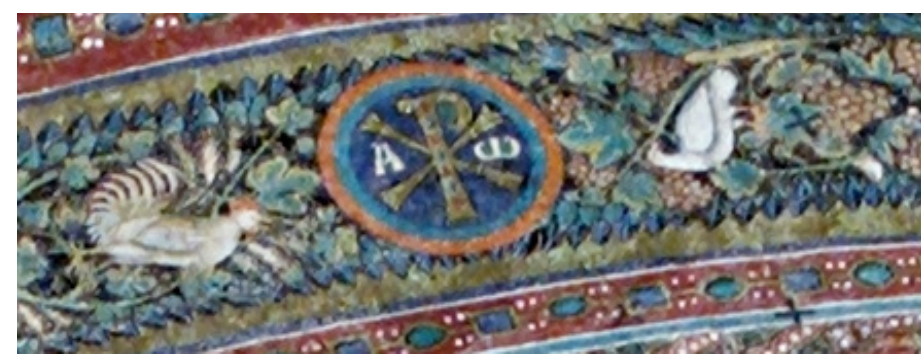

Figure 5. Christogram with alpha and omega on the triumphal arch of Santa Maria Maggiore. Fragment of Holly Hayes, "Rome: Santa Maria Maggiore," November 11, 2010, accessed May 22, 2016, https://www.flickr.com/ photos/sacred_destinations/6839704097, used in accordance with the applicable licence.

Figure 6 celebrates Christ's coronation of Maria as 'regina coeli,' queen of heaven, in line with the usual iconography linked to the sun (Christ) and the moon (Maria), respectively. Again, above the Christogram we see Christ's eternal throne, here occupied symbolically by the lamb of the Apocalypse. In its position at the top of the apse, a symbol itself of heaven, alpha and omega again convey the message that Christ, ruler of the universe, transcends time and space..$^{2}$

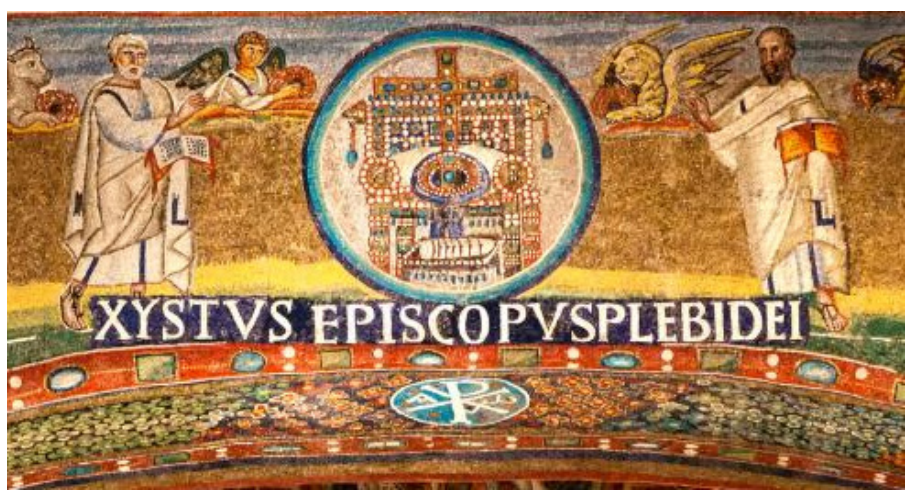

Figure 6. Christogram with alpha and omega in the apse of Santa Maria Maggiore. Fragment of Marie-Lan Nguyen, "The Coronation of the Virgin with Angels, Saints, Pope Nicolas IV and Cardinal Colonna. Apse Mosaic in Basilica di Santa Maria Maggiore, by Jacopo Torriti (1295)," January 1, 2006, accessed May 22, 2016, https://de.wikipedia.Org/wiki/Marienbildnis\#/ media/File:Apse_mosaic_SM_Maggiore.jpg, used in accordance with the applicable licence.

\section{Some conclusions}

We have seen how, over the course of the millennia, something that started out essentially as an accounting device morphed into a symbol of knowledge, perfection and even the divine: 'I am the Alpha and the Omega, the beginning and the end'. Ordering has been and is used for many other, more practical purposes. For the Greeks, it remains the preferred - and even in the Google age, at least a very important - means to access pieces of information in indices, name lists, dictionaries, encyclopaedias and much more. It is so deeply ingrained in our culture that we do not usually even perceive it for exactly what it is, a cultural construct that can be consciously used to convey meaning - something that it shares with punctuation, the other secondary characteristic that this article will examine.

\section{PUNCTUATION}

Punctuation is as much a part of written language today as are the letters themselves. It sets one sentence apart from another, indicates parts of those sentences and even parts of the words themselves. It seems all the more surprising that punctuation, or at least something resembling its current form, was invented quite recently, only about 500 years ago. Even after the conventions of punctuation had become more or less stable in early modern times, these conventions could be violated consciously to modulate the meaning of a message. This article investigates two specific cases of this happening:

- Modernist literature that would flout established punctuation rules at times to liberate the text from syntactic constraints.

- Contemporary youth literature that, by contrast, uses unconventional punctuation to constrain the meaning beyond syntax.

With regard to the latter, we will examine characters intended to convey ideas and emotions beyond letters - emoticons and emojis.

\section{History of punctuation}

Similarly to ordering, punctuation is part of school life, but is much more volatile. The rules of correct punctuation are drilled into students, although they are then often disregarded. Books in various languages on the correct application of punctuation abound. Some attempt to help the student 'to gain access to the shared conventions of formal, standard English'43 by expounding on the relevant rules. Others are somewhat unconventional - and less blatantly utilitarian - in their approach, such 
as Truss' delightful Eats, Shoots \& Leaves, which plays joyfully with the amusing ambiguities caused by ungrammatical punctuation, only to conclude that '[p]roper punctuation is both the sign and the cause of clear thinking. ${ }^{44}$ In fact, punctuation helps to disambiguate different possible meanings in a string of characters.

As with the history of ordering, the history of punctuation has been studied relatively rarely. 45 Parkes, who was a specialist in medieval palaeography by training, traced the development of Western punctuation from its beginnings in the first century $\mathrm{AD}$ as basic assistance, particularly for the inexperienced reader, to the punctuation practice of the late twentieth century. Saenger, who was curator of rare books at the Newberry Library, referred to the results of experimental psychology that showed the cognitive advant-ages of spaces.

\section{A history of a space}

In fact, by far the most frequently used of all punctuation marks in the Latin script has become so much part of our writing that we have even stopped thinking of it as a punctuation mark and are surprised that many other scripts do not actually contain it ${ }^{46}-\mathrm{I}$ am, of course, referring to the blank.

Throughout antiquity, scriptio continua or scriptura continua remained the norm. ${ }^{47}$ In most of antiquity's surviving Greek and Latin manuscripts, words were not separated, although verses sometimes were. ${ }^{48}$ It was up to the reader to add the necessary subdivisions, 'an activity requiring literary judgement and therefore one properly reserved to the reader' (Saenger, p. 11) who was supposed to be sufficiently refined to find the right moments to breathe during declamation. In this sense, writing was a tool to fix sounds, to be actualised during reading aloud. In the event of ambiguity, it was left to the reader to choose what he or she considered the most appropriate rendering. If marks to signal word boundaries to help the reader were used at all, they were optional and could be represented in a number of different ways, such as dots placed between words.

The simple use of a space as a word separator for Latin began in the early Middle Ages, in the seventh and eighth century AD, particularly in Britain and, above all, in Ireland. 49 The space was thus introduced in a context in which Latin was a foreign tongue and in which readers would not be able to parse the text based on their native command of the language. On the continent, blanks also became increasingly common during the Carolingian reforms, at a time in which Latin began to be perceived to be different from the spoken vernacular, with the trend towards adoption generally moving southward. ${ }^{\circ}$ Blanks were the norm in Latin script by the twelfth century at the latest; thus, 'the fundamental conventions of the written medium had been established. ${ }^{51}$

Whereas in classical antiquity reading almost always meant declaiming aloud, the default mode now began to change to much more rapid silent reading. Literature ceased to be a 'fundamentally acoustic phenomenon ${ }^{52}$ the model reader of which conformed to 'the ideal of the vir eloquentissimus, ${ }^{53}$ and consuming it became a primarily visual experience.

As Saenger first argued in $1982,{ }^{54}$ the introduction of blanks facilitated the reading process tremendously, relieving the reader's brain of the significant cognitive stress involved in continuously parsing the text:

In the West the ability to read silently and rapidly is the result of the historical evolution of word separation that, beginning of the seventh century, changed the format of the written page, which had to be read orally and slowly in order to be comprehended. [...] Without spaces to use for guideposts, the ancient reader needed more than twice the normal quantity of fixations and saccades per line of printed text. [...] Psychologists [...] maintain that these readers' brain would always compensate for the extra cognitive burden by more numerous ocular fixations and regressions. 55

While standardising blanks as word separators in Europe took centuries to complete, it was a major technological advance that shaped the scholarly discourse of the late Middle Ages. It was a significant, although initially perhaps an accidental step, towards the further democratisation of literacy and literature, a step away from the 'elitist literate mentality of the ancient world' (p. 11) that was not interested in making literature easily accessible to the masses.

Since then, a large part of communication depends on the quick and easy perusal of written text. Following an abstract argument in a written text is more difficult if it has to be actualised orally, and obtaining a rapid overview of the argument is almost impossible:

[...] [S]cholastic Latin, when written by a professional scribe with complete word separation, allowed the medieval scholar familiar with its conventional abbreviations, preferred modes of 
construction, and vocabulary to read swiftly and skim easily in a fashion not readily distinguishable from the perusal of a modern printed book (p. 19).

However, it was everyday literacy that was most affected. Neither newspapers nor modern novels nor, for that matter, emails and messaging would have been able to attract a readership across society if deciphering each line were a major effort. In fact, print culture - the Gutenberg Galaxy ${ }^{56}$ itself could probably not have established itself in quite its current form without the scribal innovation of the systematic demarcation of word boundaries. In this regard, the cultural and technological importance of the little whitespace for mass literacy is difficult to overstate.

\section{Dots, commata and more}

In the time of the scriptio continua, the first step in consuming a text was the praelectio or pre-reading, which by necessity involved a degree of interpretation of the text. We have already seen that this involved identifying word boundaries, but it went quite beyond this step. Quintilian elaborated on the steps required for reading in his De Institutione Oratoria:

Remains the reading: One can only show through practice, so that the boy can know where to suspend the breath, where to split the verse, where the sense finish, where it begins, where to strengthen or to lower the voice, what needs to be said with inflection, what slower, what quicker, what harder, what softer. ${ }^{57}$

As Parkes, who cited the first phrase up to 'where it begins' rightly noted, these 'are situations which we would expect to be indicated by punctuation as we understand it now' ${ }^{\prime 8}$ (Parkes mentioned the breathing marks, the lines of the verse and the sentence boundaries). Where the original Roman reader would have identified core units during the praelectio, and might or might not have marked them in her copy for easier reference, we know punctuation will give us a first view of the text, normally provided by the authors themselves. More precisely, punctuation explicates the text's syntax and grammar. However, in his citation, Parkes markedly omitted the second half of Quintilian's comment about the modulation of the voice itself ('where to strengthen ...'). These oral, interpretative aspects cannot currently be expressed via standard punctuation, the nearest approximation thereof being the exclamation mark. However, as we will see later, punctuation was concurrently developing pronun- ciation or mood markers in addition to its more classical function as a syntax marker.

Punctuation signs began to be used more regularly only following the decline of classical culture in late antiquity, particularly during the troubled years of the barracks emperors, and then initially in a form closer to stage directions than to today's punctuation. Having clear breathing marks also aided access for those newcomers less well versed in classical literature, allowing them to perform the texts they encountered correctly. Moreover, punctuation helped the correct pronunciation of the growing body of Christian texts in public, a point of particular sensitivity for the church fathers. Parkes speculated that Jerome's Vulgate might have been one of the first books to be punctuated by its author himself. ${ }^{9}$ However, using punctuation marks remained discretionary and several different sets of punctuation signs were in use.

As was the case for many other cultural phenomena, the Carolingian epoch changed the situation radically. With the death of the latino della parola ${ }^{60}$ the spoken Latin of late antiquity and of the Gothic and Merovingian periods, people became aware of the differences between the volgare they spoke every day and Latin as the language of culture and religion. Moreover, the reformers around Alcuin of York standardised the pronunciation of Latin for religious reasons, supported inter alias by an increasingly systematic approach to punctuation. Scribes made increasing use of litterae notabiliores, or more noteworthy letters, the ancestors of our capital letters. The litterae notabiliores began to be used as sentence markers, ${ }^{61}$ a rarely commented on use of letter forms as a functional equivalent of a punctuation mark.

Around this time, the positurae, the direct predecessors of today's punctuation marks, were first introduced $^{62}$ to mark up the cadences of a (primarily religious) text for oral rendering in the liturgy. Two of the marks were the direct predecessors of today's colon and question mark, respectively. The positurae were increasingly systematised over the centuries. Modern punctuation marks were largely in place from the twelfth century onwards, based on the positurae, although the specific character shapes and rules of usage remained variable.

Character shapes and the usage of punctuation marks largely stabilised only with and due to the printing press and movable types in the late fifteenth century. In the beginning, the different typefaces also had a certain degree of variability. However, through the dominance of Italian humanism during the epoch and the (related) early success of Venice as a printing centre, the choices of the 
Venetian printing press and particularly those of Aldus Manutius, its leading printer, and Francesco Griffo, his typecutter, held sway.

The publication of Pietro Bembo's De Aetna in 1495 athe same Pietro Bembo whose Prose della Volgar Lingua ${ }^{63}$ helped so much to standardise the Italian language - introduced the semicolon in addition to the other punctuation marks, which was a true innovation by Aldus Manutius. ${ }^{64}$

\section{PETRI BEMBI DE AETNA AD ANGELVM CHABRIELEM LIBER.}

Factum a nobis pueris eft, et quidem fedulo Angele; quod meminiffe te certo fcio;ut fructus ftudiorum noftrorum, quos ferebat illa aetas nó tam maturos, $\ddot{q}$ uberes,femper tibialiquos promeremus: nam fiuedolebasaliquid, fue gaudebas; quaeduo funt tenerorum animorum ma xime propriaeaffectiones; continuo habebasaliquid a me, quod legeres, uel gratulationis,uel confolationis;imbecillum tu quidem illud, et tenue; ficuti nafcentia omnia,etincipientia;fed tamen quod effet fatisamplum futurum argumentum amorisfummi erga temei. Verum poftea, đ̆ annis crefcentibus et ftudia,et iudi cium increuere; nófq; totos tradidimus graecis magiftris erudiendos; remiffiores paulatim facti fumusad fcribendum, ac iam etiam minus quotidie audentiores.

\footnotetext{
Figure 7. First page of Pietro Bembo, De Aetna (Venice: Aldo Manuzio, 1495), showing the use of the semicolon to structure long sentences.
}

The grandson of Aldus Manutius, Aldus Manutius the Younger, systematised his grandfather's lessons in his massive Orthographiae ratio. ${ }^{65}$ As the book's name suggests, it addresses (Latin) orthography in general, citing numerous sources for the choices made. The book has, however, a short annex, the interpungendi ratio on punctuation (p. 791-80o). It sees punctuation as an integral aspect of orthography. ${ }^{66}$ This is a far cry from the original idea of breathing marks or even of the positurae to enhance oral renderings of the text. The leading medium in the Renaissance was now the written text, more specifically the printed text, not its actualisation via oral performance. Punctuation became a means to make the structure of the written text apparent. Aldus Manutius the Younger presented each punctuation mark in turn with corresponding examples taken from editions of classical Latin authors, the latter a classical humanist topos to project their choices, consciously or unconsciously, ahistorically into classical antiquity:

- the comma |,| or 'semi-punctum', 'sententiae partes terminat' (p. 795),

- the semicolon |;| originally meant to mark contrasts ('distinguit contraria nomina', p. 795),

- the colon |:| or 'geminatio puncti' (p. 796),

- the full stop |.| or 'punctus', 'quo sententia con cluditur' (p. 797),

- the question mark or 'interrogandi nota' (p. 798), which Manutius considered unneces sary for Latin, as its syntax already clarifies this, and

- parentheses, the usage of which seems to be been uncontested ('de paranthesi pauca dicam', p. 799).

Of these, Manutius' invention, the semicolon, took most time to be generally adopted. It is still the most volatile of punctuation signs. With regard to the others, both in appearance and in usage, little has changed since Manutius the Younger's prescriptions and today's rules. The one punctuation mark that is missing entirely in Manutius' list, the exclamation mark, remains the most oral of punctuation marks, and the one that is traditionally used almost exclusively for rendering direct speech in literature.

Some languages in the Latin tradition developed their own punctuation marks, such as the inverted question $(i)$ and exclamation $(j)$ marks in Spanish. ${ }^{67}$ Other marks, such as the percontation point (؟) to mark rhetorical questions, proposed by the English printer Henry Denham, were only popular for a few decades before disappearing, ${ }^{68}$ as did the interrobang?, a cross between question and exclamation mark. During the sixteenth and seventeenth centuries, various specialised punctuation marks that have no equivalence in speech at all were introduced, including specific parentheses, footnote markers such as ${ }^{*}$ or ${ }^{*}$, quotation marks and the like. These characters became part of the genuinely typographic tradition without ever being considered part of the core orthography, with the exception of quotation marks.

\section{The role of punctuaton}

If punctuation was originally primarily a means to help people to read aloud, its role in the Gutenberg 
Galaxy is quite different. Punctuation still has the role of a praelectio provided by the author, and it has been very successful in this role. It is indeed astonishing how such a tiny, but adaptable system of marks allows us to notate most (but not all) types of verbal expression. ${ }^{69}$ However, since the sixteenth century, punctuation has been above all a feature of a writing system - until about a decade ago:

Most significantly of all, however, they [the rules set out by the Manutius family] ignored the old marks that had aided the reader-aloud. Books were now for reading and understanding, not intoning. [...] Within the seventy years it took for Aldus Manutius the Elder to be replaced by Aldus Manutius the Younger, things had changed so drastically that in 1566 Aldus Manutius the Younger was able to state that the main object of punctuation was the clarification of syntax..$^{\circ}$

If we discard purely pecuniary arguments such as those advanced by Peck and Coyle in The Student's Guide to Writing, the main argument for standardised orthography and punctuation is indeed ease of reading. As Parkes elaborated, standardised punctuation and particularly word separation facilitate the speedy perusal of texts, a precondition for amassing large quantities of information easily. It is advantageous to invest time and energy in mastering the shared conventions of orthography and punctuation for society as whole in return for quicker and easier access to information.

\section{After the agony in stony places / the shouting and the crying}

Around the turn of the nineteenth to the twentieth centuries, a large section of the artistic youth became increasingly dissatisfied with what it perceived as the stagnation of the Victorian period. Grossly oversimplifying, the resulting movement, Modernism, was a rebellion against the restrictions of Victorian morality and what was seen as its shallow materialism, optimism and liberalism. Loud shouts replaced Victorian whispers.

This rebellion touched all aspects of art, philosophy and culture in its widest sense. In the arts, it broke with the conventions of pictorial representation, harking back to forms that were seen as more basic and perennial. In poetry, it radicalised the break with poetic form that had begun with the poètes maudits, mainly by Jules Laforgue. ${ }^{71}$ Poetry was to be free from predefined metrics and rhyme schemes, although it might still embrace them if demanded by the occasion, and was malleable to express the narrator's consciousness.

The stream of consciousness technique became a hallmark of Modernism in literature. The schoolbook example is Molly Bloom's interior monologue at the end of Ulysses, where Molly contemplates her difficult relationship with her husband. This monologue is famous for possibly being world literature's longest sentence, spanning 23 printed pages from 'Mulveys was the first' 72 to its famous conclusion 'I put my arms around him yes and drew him down to me so he could feel my breasts all perfume yes and his heart was going like mad and yes I said yes I will Yes.'73 No punctuation marks interrupt her thoughts until the final full stop that signs her commitment. The absence of punctuation liberates the text from syntactic constraints to mirror an unstructured flow of thoughts.

In his quasi-contemporaneous masterpiece, The Waste Land, T.S. Eliot used the same technique in the fifth and final chant, "What the Thunder Said":

Here is no water, but only rock Rock and no water and the sandy road The road winding above among the mountains ${ }^{74}$

T.S. Eliot was no revolutionary in the use of punctuation. He deviated from the grammatical norm only in somewhat exceptional cases. That being said, he would also use ungrammatical punctuation to constrain interpretation very occasionally, with more than slight anti-Semitic overtones in his 1920 poem "A Cooking Egg":

I shall not want Capital in Heaven

For I shall meet Sir Alfred Mond.

We two shall lie together, lapt

In a five per cent. Exchequer Bond. ${ }^{75}$

Some Modernist poets also walked the last mile and exploited not only punctuation - or its absence - , but also page layout, capitalisation and font styles. This short extract from Ezra Pound's Canto LXXIII shows some of this in action, as well as demonstrating his commitment to literary allusions across his personal $A B C$ of reading:

in the drenched tent there is quiet sered eyes are at rest

the rain beat as with colour of feldspar

blue as the flying fish of Zoagli pax, ǔס $\omega \rho$ ${ }^{\prime} \mathrm{Y} \Delta \Omega \mathrm{P}^{76}$

As Michael Dirda rightly noted in his introduction, Pound's aphoristic prose style is, in many ways, almost that of a 'modern-day blogger.' 77 More than blogs, his aphorisms are tweets avant la 
lèttre, ranging from the sublime to the plainly unhinged, while the idiosyncratic capitalisation 'Rhythm is a form cut into TIME, as design is determined $\mathrm{SPACE}^{77^{8}}$ - prefigures the next evolution of punctuation. ${ }^{79}$

\section{You. People. Are. Crazy!}

'You. People. Are. Crazy!' The words started low, but rose to a scream as she mounted the stairs. She slammed the door to her room, and once inside stood in the middle of it, starting around her, bewildered. ${ }^{80}$

The fifteen-year old heroine of the popular teenage mystery novel series Night School, Allie Sheridan, becomes very upset when she learns of her parents' plans to send her to boarding school without consulting her. The punctuation of the sentence mirrors her rage directly. By flouting all grammatical rules governing the use of the full stop in English, punctuation becomes once more an aid to pronunciation, making this a very close rendering of spoken language. Furthermore, the reader is drawn not only into Allie's orality, but directly into her mind, just by reading these sentences.

This pattern recurs to signal moments of emotional turmoil during the story. When Allie has trouble with who later will become her second boyfriend at the boarding school, she screams at him: 'You don't. Ignore somebody. For Weeks. And then. Ask them. Personal questions. You. Arsehole.' (p. 184). Similarly, when she falls out with her first boyfriend and dance partner, she shouts 'And we. Are So. Over.' (p. 238).

Allie is not alone in her special, asyntactic use of punctuation. Here an example of an action scene - the heroine and her companions are battling horrific monsters - from another teenage fantasy novel in which the heroine is Kit Blackhart:

'No. They were all more interested in arguing than listening to me, so I left. I'm sure we'll be saved any second now.' I raise my voice, hoping that the scorpion hybrid or Istvan or anyone else is listening and will let us go. 'Any. Second. Now. ${ }^{,{ }_{1}}$

Generally, the pacing of the story is quick in action scenes. The impressions in this almost stream-of-consciousness account of the heroine's actions are conveyed through a rapid-fire sequence of short sentences. The dominant punctuation mark is the full-stop, separating the individual cuts of this scene (it is difficult to not visualise the actions as shots in a video clip).
It is hardly a coincidence that this usage seems particularly common in novels targeted at a young, mainly teenage audience. This audience is most likely to be at the forefront of innovation, most influenced by new forms of electronic communication and more familiar with the rapid sequences of shots in YouTube clips. This development is still in full flow, and it is by no means restricted to novels. It ranges from the German army's advertising slogan, 'Wir. Dienen. Deutschland.' (We. Serve. Germany.), which attempts to curry favour with youth, to an advertisement at the Leonardo da Vinci airport in Fiumicino (Figure 8).

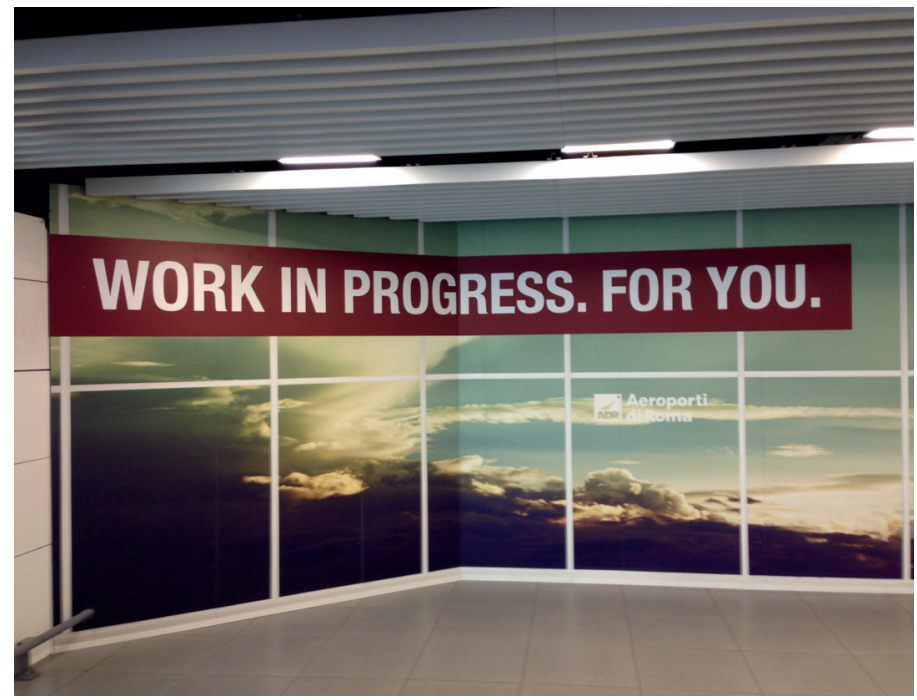

Figure 8. Announcement in the Leonardo da Vinci airport. Photo taken on May 16, 2016.

If Aldus Manutius defined rules to highlight syntax rather than pronunciation, these examples are in the process of returning to the origins of punctuation as breathing marks, governed by the needs of spoken language. In this sense, they finish the explication of Quintilian's analysis in the praelectio by marking emotional states and moods in conjunction with the syntactical structure of the text. At this stage, this is far from a general trend, although the general punctuation trends, at least in young adult and urban fantasy literature, seem to be approaching closer proximity to spoken language.

\section{Emoticons and Emoji}

If already traditional punctuation marks are increasingly used to explicate the intended moods and emotions in text, this is of course even more true for the numerous signs, from the all-time favourite :- $)^{82}$ and $" v$ to $\left(\cdot \omega_{\bullet}\right)$, invented specifically to encode emotions. The terms emoticon ${ }^{8_{3}}$ and emoji are often used interchangeably to refer to any type of sign that encodes emotions, often, but not necessarily, in short messages. However, strictly speaking, these terms are not synonymous. Amongst 
the numerous, sometimes conflicting definitions, the one given by the Unicode consortium is probably the nearest to an official one:

Emoji are 'picture characters' originally associated with cellular telephone usage in Japan, but now popular worldwide. The word emoji comes from the Japanese [...]

Emoji are often pictographs - images of things such as faces, weather, vehicles and buildings, food and drink, animals and plants - or icons that represent emotions, feelings, or activities.

Emoticons (from 'emotion' plus 'icon') are specifically intended to depict facial expression or body posture as a way of conveying emotion or attitude in e-mail and text messages. They originated as ASCII character combinations such as :-) to indicate a smile - and by extension, a joke - and :-( to indicate a frown..$^{8}$

In other words, an emoticon is a character or sequence of characters related to human emotions, whereas an emoji is a Unicode character representing any number of objects or emotions. Some emojis, such as (우 or , are also emoticons, while others such as , or are depictions of the respective objects. Still others, such as 17 are actually depictions of abstract concepts (a day in this case), while others such as $\checkmark$ are both a depiction of an object and are imbued with an (in this case) obvious double meaning.

In the last few years, emojis have taken on an astonishing life of their own. ${ }^{85}$ In current versions of Apple's iOS operating system, which drives the iPhone and iPad, the only second keyboard offered by default is a keyboard containing emojis. On May 5, 2016, the Unicode Consortium felt the need to send an announcement to the subscribers on its mailing list to point out that Unicode is 'Not Just Emoji', acknowledging however that '[t]he awareness of the Unicode Consortium has grown recently, with the spread of emoji'. Emojis are regularly used in email exchanges - normally in the form of emoticons - but are omnipresent in short messaging, tweets and similar short, informal means of communication. As Unicode encodes only the basic meaning of a character, not its appearance, ${ }^{86}$ this regularly gives rise to misunderstandings, as the supposedly same character may be interpreted very differently by the sender and the recipient. This is a representation of the popular emoji for partying women 19 , which, in Windows different, much tamer idea. ${ }^{87}$

Emojis are, however, leaving their corner as mood markers and are, at least experimentally, crossing over into a proto-writing system. Artistic experiments such as Emoji Dick ${ }^{88}$ - a full rendering of Moby Dick in emoji - have solicited significant echoes in the press. Tongue-in-cheek dictionaries such as How to Speak Emoji Love ${ }^{89}$ try to teach the art of writing love messages in emoji. However, Benenson's How to Speak Emoji actually goes a step further by identifying techniques used to write arbitrary words in emoji. It is interesting that these are essentially the same strategies as those used during the creation of writing itself:

- Translating a term literally (logograms)

- Applying the rebus principle by using an emoji's phonetic value

- Exploiting visual similarities

- Combining emojis to build phrases

- Using certain emojis as semantic markers

Of course, emojis will over time at best complement, not fundamentally change the Western alphabetic writing system and our current system of punctuation. We will not move back in time from a full alphabetic writing with an elaborate system of related secondary characteristics to a combination of logographic and syllabic characters based on funny fashionable icons. Will we ? 


\section{NOTES}

1. Peter T. Daniels, "Grammatology: Introduction," in The World's Writing Systems, ed. Peter T. Daniels and William Bright (Oxford University Press, 1996), 1.

2. Ignace J. Gelb, A Study of Writing, and ed. (Chicago: University of Chicago Press, 1963) hypothesises in chapter VIII that all writing systems are direct or indirect descendants from, or at least are inspired by, cuneiform writing (the monogenesis of writing). This hypothesis was disproved by the discovery that the Mayan hieroglyphs constituted a full, independently developed writing system. It is, however, not impossible that Chinese writing was somehow influenced by Sumerian writing during the Shang dynasty, as Gelb assumed. Cf. Robert W. Bagley, "Anyang writing and the origin of the Chinese writing system" in The First Writing: Script Invention as History and Process, ed. Stephen D. Houston (New York, Oxford: Cambridge University Press, 2004), 190-249 for a fuller discussion of the earliest known samples of Chinese writing. With regard to Sumerian and Egyptian writing, the most common assumption is that the idea of writing spread from Sumer to Egypt, although the direction of borrowing is not unchallenged (cf. John Baines, "The Earliest Egyptian Writing: Development, Context, Purpose," in Houston, The First Writing, 150-189, passim and in particular p. 154 ff for more details)

3. Charles Sanders Peirce, The Essential Peirce: Selected Philosophical Writings, ed. Nathan et al. Houser, vol. 2 (1893-1913) (Bloomington: Indiana University Press, 1998), 143, in the second volume = Collected Papers (CP), 2.248 .

4. Denise Schmandt-Besserat, How Writing Came About (Austin, Texas: University of Texas Press, 1996), 72-78.

5. The rebus principle is discussed in most histories of writing, e.g. Gelb, A Study of Writing, in particular p. $97 \mathrm{ff}$. As Gelb stressed, cuneiform never lost its pictographic origins entirely, having in the end three classes of signs: logograms / pictograms as 'signs for words of the language', syllabic signs, 'developed by the rebus principle from logograms' and auxiliary marks, such as punctuation marks, classifiers, or determinatives (cf. Gelb, p. 99).

6. As the founder of grammatology, Ignace Gelb, put it: 'writing in the widest sense cannot be in all stages identified with speech, and a student of writing does not necessarily have to be a linguist', ibid., 10.

7. This colour-word interference is known as the Stroop effect and was originally discovered in the 1920 and 1930s. It has since been repeatedly reconfirmed, e.g. in Leslie A. Fox, Ronald E. Shor, and Robert J. Steinman, "Semantic Gradients and Interference in Naming Color, Spatial Direction, and Numerosity," Journal of Experimental Psychology 91, no. 1 (1971): 59-65.

8. Cf. Marc Wilhelm Küster, Geordnetes Weltbild (Tubingen: Niemeyer, 2006), $56 \mathrm{ff}$.

9. For some off-the-shelf examples from the Astérix comics cf. René Goscinny and Albert Uderzo, Astérix légionnaire, 1st ed., vol. 10 (Hachette (Educa Books), 2005), 25, 36ff; René Goscinny and Albert Uderzo, Obélix et Compagnie, vol. 23 (Hachette, 1976); 27 and René Goscinny and Albert Uderzo, La zizanie, vol. 15 (2005), 15, unfortunately impossible to reproduce here for copyright reasons. As an aside, the fishmonger in that series is called Ordralfabétix (= ordre alphabétique).

10. CEN TC304, EN 13710:201: European Ordering Rules - Ordering of characters from Latin, Greek, Cyrillic, Georgian and Armenian scripts, European Standard (CEN, March 16, 2011), 3.4, citing in turn ISO/IEC JTC 1/SC 2, ISO/IEC 14651:2016: Information Technology - International String Ordering and Comparison - Method for Comparing Character Strings and Description of the Common Template Tailorable Ordering.

11. Transliterations and Translations after Oracc, "Digital Corpus of Cuneiform Lexical Texts (DCCLT)," July 23, 2014, accessed May 11, 2016, http://oracc.museum.upenn.edu/dcclt/declt_intro.html, entry ED Lu A, citing the list's Early Dynastic version.

12. Baines, "The Earliest Egyptian Writing", 151.
13. Cf. Wolfram von Soden, Sumer, Babylon und Hethiter bis zur Mitte des zweiten Jahrtausends v. Chr., Propyläen Weltgeschichte 1 (Berlin: Ullstein Verlag, 1961), 565 .

14. Ebla is situated in present-day Syria, not too far from Aleppo.

15. Cf. Giovanni Pettinato, Testi lessicali monolingui della biblioteca L. 2769, vol. 3, Materiali epigrafici di Ebla (Napoli, 1981), the definitive edition of monolingual lexical lists found in Ebla.

16. See Hans H. Wellisch, "Ebla: The World's Oldest Library," Journal of Library History 16, no. 3 (1981): 488-500, 49off, where Wellisch also discussed whether this collection of about fifteen thousand tablets is, in today's terms, an archive or a library, concluding that it can actually be called a library.

17. Ibid., 494.

18. Pettinato, Testi lessicali monolingui della biblioteca L. 2769, 187, all previously known syllabaries came from a period during which Sumerian was no longer spoken.

19. Ibid., lists no. 61 and 62 .

20. Alfonso Archi, "Ebla Texts," in The Oxford Encyclopedia of Archaeology in the Near East, by editor in chief, prepared under the auspices of the American Schools of Oriental Research, Eric M. Meyers (Oxford Univ. Press, 1997), 185 .

21. Baines, "The Earliest Egyptian Writing", 16o, cf. also Robert K. Ritner, "Egyptian Writing," in Daniels and Bright, The World's Writing Systems, $81 f f$.

22. Alan H. Gardiner, "The Egyptian Origin of the Semitic Alphabet," The Journal of Egyptian Archaeology 3, no. 1 (1916): 1-16.

23. Gardiner, "The Egyptian Origin", 12.

24. Ibid., 16.

25. Ibid., 7. This is incidentally exactly the same principle that many books for young children till use today when they depict a suitable object to illustrate each letter in the alphabet.

26. John Coleman Darnell et al. "Two Early Alphabetic Inscriptions from the Wadi el-Hồ: New Evidence for the Origin of the Alphabet from the Western Desert of Egypt," in Annual of the American Schools of Oriental Research, ed. Meredith S. Chesson et al., vol. 59 (American Schools of Oriental Research, 2006), 85ff.

27. This latter is the hypothesis by Ibid., 91, who ascribed script invention to the 'interaction between Asiatic mercenaries and Egyptian military scribes.'

28. See Alan H. Gardiner, Ancient Egyptian Onomastica, 3 vols. (Oxford: Oxford University Press, 1947), 6.

29. Cf. e.g. Wolfgang Rollig, "Nordsemitisch - Südsemitisch? Zur Geschichte des Alphabets im 2. Jt. v. Chr.," Israel Oriental Studies, no. 18 (1998): 84 .

30. In Küster, Geordnetes Weltbild, 167, I attempted a possible reconstruction of the North Semitic order using the semantic clusters home, animal husbandry and agriculture, textile production, water and body, ending with the abstract sign taw, the last character of the Phoenician alphabet and thus symbol of writing itself.

31. L.H. Jeffery, The Local Scripts of Archaic Greece: a Study of the Origin of the Greek Alphabet and its Development from the Eighth to the Fifth Centuries B. C. (Oxford University Press, 1990) is the definitive overview of Greek alphabet variants up to $403 \mathrm{BC}$. In the very beginning, the writing direction was largely right-to-left, but it quickly became predominantly boustrophedon, where the writing direction changes in each line. The script standardised to today's left-to-right writing direction slowly and at different speeds.

32. For this reason, CEN TC304, EN 13710:2011 gives the full sequence of 


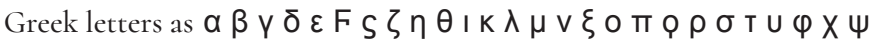
$\omega \ni$. The letter stigma $S$ had a particularly strange history, as it derives historically from the digamma $F$, but was reinterpreted as a ligature of sigma and tau in Byzantine times. If used as a number character, it shares the same numerical value of $F, 6$.

33. Cf. Hermann Usener, "Hermanni Vseneri lectiones Graecae," Rheinisches Museum für Philologie 25 (1870): 591.

34. Aristoteles, Metaphysics Books X-XIV, Oeconomic and Magna Moralia, trans. Hugh Tredennick and G. Cyril Armstrong, vol. 2, Loeb Classical Library (London, Cambridge, MA: William Heinemann, Harvard University Press, 1962), 301 (= Aristotle, Metaphysics, XIV, chap. VI, §8). Aristotle mocked this Pythagorean position.

35. E.G. Turner, The Hibeh Papyrii, vol. 2, 2 (London: Egypt Exploration Society, 1955), 15 .

36. Küster, Geordnetes Weltbild, ch. 12.

37. Cf. Benjamin D. Giffone, "A 'Perfect' Poem: The Use of the Qatal Verbal Form in the Biblical Acrostics," Hebrew Studies 51 (2010): 53 f.

38. Cf. William Michael Soil, "Babylonian and Biblical Acrostics," Biblica 69, no. 3 (1988): 305 and passim, http://www.jstor.org/stable/42707419.

39. Cf. P.A. Munch, "Die alphabetische Akrostichie in der jüdischen Psalmendichtung," Zeitschrift der Deutschen Morgenländischen Gesellschaft 9o. (n.F. 15), no. 3/4 (1936): 703-71 for some examples, in particular p. 7o6ff.

40. Soll, "Babylonian and Biblical Acrostics," 317.

41. Cf. Giovanna Paccanelli and Gianfranco Sabatini, eds., I mosaici del V secolo: Basilica papale di Santa Maria Maggiore (Citta del Vaticano, 2015), 70.

42. The apse of Santa Maria Trastevere Roma uses similar iconography in its $13^{\text {th }}$ century mosaic, although it divides the Christogram form and the depiction of alpha and omega with a cross, as do countless lesser-known churches across the world. Wendy Pullan, "Jerusalem from Alpha to Omega in the Santa Pudenziana Mosaic," Jewish Art, no. 23-24 (1998): 405417 and Fredric W. Schlatter, "Interpreting the Mosaic of Santa Pudenziana," Vigiliae Christianae 46, no. 3 (1992): 276-295 also discussed the mosaic on the apse of the nearby Basilica of Santa Pudenziana. In a more secular context, A-Z plays the same role in symbolising the totality of knowledge. Amongst many possible examples, just one that has had direct impacted on the creation of this work is the central library website of Luxembourg, which has as its URL http:// www.a-z.lu.

43. See, for example, John Peck and Martin Coyle, The Student's Guide to Writing: Spelling, Punctuation and Grammar, 2nd ed. (Hampshire: Palgrave Macmillan, 2005), viii. It is interesting that this guide no longer trusts the concept of 'correct' and 'right' in spelling, but motivates those conventions in purely utilitarian terms instead, "because they are the conventions of those who make decisions and influence the lives of the rest of us' (p. vii).

44. Lynne Truss, Eats, Shoots \& Leaves (London: Profile Books, 2003), 202.

45. Truss herself does provide a short introduction to the history of punctuation marks, but the definitive studies remain Malcolm B. Parkes, Pause and Effect: An Introduction to the History of Punctuation in the West, Reprinted 2012 (Farnham, Surrey: Ashgate, 1992) for punctuation in general and Paul Saenger, Space Between Words: the Origins of Silent Reading (Stanford University Press, 2000) in particular for the role of the whitespace.

46. Other scripts, such as the Indic family of scripts, i.e. the descendants of the Brāhmī script, do not normally use word separators to this day. Cf. Richard G. Salomon, "Brahmi and Kharoshthi," in The World's Writing Systems, ed. Peter T. Daniels and William Bright (New York, Oxford: Oxford University Press, 1996), 373-383 for more information on the characteristics of the Brāhmī script. Other scripts such as Chinese writing only adopted blanks during the twentieth century under Western influence, cf. Victor H. Mair, "Modern Chinese Writing," in Daniels and Bright, The World's Writing Systems, 201.

47. In scriptio continua, words are written in a continuous stream of letters, leaving it up to the reader to ascertain word boundaries; for example, tobeornotto bethatisthequestion. A late-antiquity Latin example is shown in Figure 5.
48. Words in the Phoenician script and its direct descendants have always been separated by either spaces or points, cf. Saenger, Space Between Words, 9 .

49. Cf. Parkes, Pause and Effect, 22.

50. Cf. Saenger, Space Between Words, 21ff. Vernacular texts continued to be written in scriptio continua in Britain and Ireland for centuries to come, cf. ibid., 34, underlining that blanks were initially a reading aid for a foreign language rather than an inherent part of the writing system.

51. Parkes, Pause and Effect, 41.

52. Rene Nünlist, "Users of Literature," in A Companion to Greek Literature, ed. Martin Hose and David 53. 53 Schenker (Wiley-Blackwell, 2015), 296.

53. Saenger, Space Between Words, 9, emphasis in the original.

54. Paul Saenger, "Silent Reading: Its Impact on Late Medieval Script and Society," Viator 13 (1982): 367-414.

55. Saenger, Space Between Words, 6f. A saccade is 'the movement of the eye when it makes a sudden change of fixation, as in reading', Collins ed., "Collins English Dictionary - Complete \& Unabridged 1oth Edition," May 2016, http://www.dictionary.com/browse/saccade, i.e. a measure of the intensity of eye movement during reading. Saenger's conclusions have been challenged, e.g. A.K. Gavrilov, "Techniques of Reading in Classical Antiquity," The Classical Quarterly 47, no. 1 (1997): 56, maintained that 'the phenomenon of reading itself is fundamentally the same in modern and in ancient culture' (p. 69), which in turn has been - in my view convincingly - refuted in Nünlist, "Users of Literature". Reading is a cultural skill that, as are all other cultural phenomena, is shaped by technological advances.

56. Marshall McLuhan, The Gutenberg Galaxy. The Making of Typographic Man. (Toronto: University of Toronto Press, 1962).

57. Cited after Marcus Fabius Quintilianus, De institutione oratoria, ed. Jean Joseph Dussault and Georg Ludwig Spalding, vol. 1 (Paris: Lemaire, 1821), Lib I, 8. My translation of the original: superest lectio: in qua puer ut sciat ubi suspendere spiritum debeat, quo loco versum distinguere, ubi claudatur sensus, unde incipiat, quando attollenda vel summittenda sit vox, quid quoque flexu, quid lentius, celerius, concitatius, lenius dicendum; demonstrari nisi in opere ipso non potest.

58. Parkes, Pause and Effect, 11.

59. Ibid., 15 .

6o. Cf. also Maria Luisa Meneghetti, Le origini delle letterature medievali romanze, Storia delle Letterature Medievali Romanze 1 (Roma, Bari: Laterza, 1997), ch. 2.5, Florian Coulmas, Writing Systems: An Introduction to Their Linguistic Analysis, Cambridge Textbooks in Linguistics (Cambridge University Press, 2003), 227ff and Küster, Geordnetes Weltbild, $378 \mathrm{ff}$.

61. Parkes, Pause and Effect, 34.

62. Ibid., ch. 4 remarked that the positurae, the origins of which are still unclear, were becoming popular 'during the course of the second half of the eighth century' (p. 35). They 'fulfilled the need for more accurate indication of the nature of the pauses required to elucidate the sense of a text when it was to be intoned or sung in the liturgy' (p. 36).

63. Pietro Bembo, Prose della Volgar Lingua: L'editio princeps del 1525 riscontrata con I'autografo Vaticano latino 3210, ed. Claudio Vela, Testi e Studi di Filologia e Letteratura 5 (Bologna: CLUEB).

64. Cf. Truss, Eats, Shoots \& Leaves, 77.

65. Aldo Manuzio, Orthographiae ratio (Venice: Aldo Manuzio iunior, 1566.

66. 'Interpungendi rationem ad Orthographiam pertinere [...] elaborabimus', ibid., 793 .

67. These punctuation marks were originally introduced by Real Academia Espanola, Ortografia de la lengua castellana, Nueva edicion corregida y aumentada (Madrid, 1754), but were only slowly accepted as general usage.

68. Cf. Truss, Eats, Shoots \& Leaves, 142.

69. Ibid., 34 . 
70. Truss, Eats, Shoots \& Leaves, 78.

71. Jules Laforgue, Poésies Complètes II: L'imitation de Notre-Dame la Lune. Le Concile féerique. Des Fleurs de bonne volonté. Derniers vers, and ed., Poésie (Paris: Gallimard, 1979).

72. James Joyce, Ulysses (Shakespeare \& Co, 1922), 710.

73. Ibid., 732.

74. T.S. Eliot, The Complete Poems and Plays of T.S. Eliot, Reprint (Faber / Faber, 1969$), 72$.

75. Ibid., 44, making double allusion to the British and Zionist industrialist and financier Alfred Mond and the German word Mond (moon).

76. Canto LXXIII, Ezra Pound, The Cantos of Ezra Pound, Fourth Collected Edition, fifth impression (Faber / Faber, 1998), 543.

77. Ezra Pound, $A B C$ of Reading, with an introduction by Michael Dirda (New Directions Pub. Corp., 2010), 10.

78. Ibid., 196.

79. The author would like to thank the anonymous reviewer for the suggestion to add a section on modernist punctuation.

8o. C.J. Daugherty, Night School (Atom, 2012), 14 .

81. Liz de Jager, Banished. The Blackhart Legacy, Book 1 (Tor, 2014), ch. 43 , my emphasis. Again, this is a recurring pattern. In Liz de Jager, Vowed. The Blackhart Legacy, Book 2 (Tor, 2014), 36, Kit banters with her cousin: "When is the meeting?" "Tonight. Midnight. At Milton's." Similar examples abound.

82. Scott E. Fahlman, "Smiley Lore :-)," http://www. cs.cmu.edu/ sef/ sefSmiley.htm, accessed May 11, 2016 dated the invention, or at least the popularisation, of the smiley or emoticon in its current form to 1982 . Fahlman is actually quite ambiguous about his invention: 'Perhaps the E-mail smiley face has done more to degrade our written communication than to improve it'. Other emoticon-like constructs had already appeared in an 1881 magazine without gaining much traction at that stage, cf. Scott Christianson, 100 Diagrams That Changed the World: From the Earliest Cave Paintings to the Innovation of the iPod, (Penguin Group (USA) Incorporated, 2012), 158.

83. 'You will know about emoticons. Emoticons are the proper name for smileys. And a smiley is, famously, this: :-)' Truss, Eats, Shoots \& Leaves, $192 f f$.

84. Unicode Consortium, "FAQ - Emoji and Dingbats," March 30, 2016, accessed May 11, 2016, http://unicode.org/faq/emoji_dingbats.html.

85.There are actually hundreds of them, cf. M. Davis and P. Edberg, eds., Unicode Emoji (= Unicode Technical Report \#51) (Unicode Consortium, 2015), http://www.unicode.org/reports/tr51 (at the moment of writing, 1624 emojis are encoded in the Unicode standard).

86. Unicode is fundamentally built on the distinction between the character as a logical entity and its glyphs, i.e. its concrete representations in a given font, cf. also Yannis Haralambous, Fonts \& Encodings, trans. P. Scott Horne (O'Reilly Media, 2007), passim.

87. See Unicode Consortium, "Full Emoji Data," April 17, 2016, accessed May 11, 2016, http://www.unicode.org/emoji/charts/full-emoji-list.html for different representations for emojis on popular platforms. Fred Benenson, How to Speak Emoji (Ebury Press, 2015), 11 explained that this emoji is ' $t \mathrm{t}$ ] ypically used to symbolise friendship'.

88. Herman Melville, Emoji Dick, or, The Whale, 1st ed., ed. Fred Benenson, trans. Amazon Mechanical Turk (Virginia, 2010).

89. Ebury Press, ed., How to Speak Emoji Love (Ebury Press, 2016). Benenson, How to Speak Emoji, 6, which, however, lists only the first four principles. I have added the fifth, observing that the book uses e.g. as a generic determinative for negation.
BIOGRAPHY

Marc Wilhelm Küster holds a degree in Physics, a Master in Philology and History and a PhD in Modern Philology from Tübingen University with a dissertation on the tradition of alphabetic ordering from cuneiform to computers (Geordnetes Weltbild). After working in the field of literary and documentary data processing and then co-founding the XML company Saphor $\mathrm{GmbH}$, he became Professor for Web Services and XML Technologies at the University of Applied Sciences Worms. Marc Küster has researched on Semantic Web, XML technologies, and distributed systems with applications in the Digital Humanities. He has been active in European and international standardization, amongst others as editor of EN 13710 "European ordering rules" and as chair of CEN/TC304 "European localization requirements". In 2008 Marc joined the Publication Office of the European Union, since 2011 as head of sector "Storage and Electronic Archive".

\section{KEYWORDS}

- Grammatology
- Ordering
- Writing
- Punctuation
- Emoji

